\title{
Study on Prevalence of Ovine Paramphistomiasis in Kutaber Woreda, South Wollo, Amhara Region, Ethiopia
}

\author{
Kindu Wondmnew*, Wossen Temesgen, Mohammed Hussien and Yeshiwork Arega \\ Kutaber Woreda Livestock Resource Development Office, Ethiopia \\ *Corresponding author: Kindu Wondmnew, Kutaber Woreda Livestock Resource Development Office, Kutaber Woreda, South Wollo \\ Zone, Amhara region, Ethiopia. \\ To Cite This Article: Kindu Wondmnew. Study on Prevalence of Ovine Paramphistomiasis in Kutaber Woreda, South Wollo, Amhara Region, \\ Ethiopia. Am J Biomed Sci \& Res. 2019 - 5(2). AJBSR.MS.ID.000889. DOI: 10.34297/AJBSR.2019.05.000889.
}

Received: 眥July 31, 2019; Published: 眥 September 16, 2019

\begin{abstract}
A study was conducted to identify the current status of paraphisthomum infections in small ruminants in Kutaber. A total of 384 faecal samples from small ruminants were collected and subjected to sedimentation technique. Out of 384 faecal samples inspected, 150 (39.1\%) were positive for Paraphisthomum. Prevalence of $36.5 \%$, and $30.8 \%$ were observed in good and medium body condition. In adult and young sheep prevalence of $40.9 \%$ and $33.3 \%$ were identified from faecal samples inspected respectively. The highest prevalence of Paramphistomiasis was observed in Lewcho (50.0\%) followed by Beshilo (44.5\%) and Elsa (42.1\%). The lowest prevalence of Paramphistomiasis was observed in Alansha (19.0\%). Based on age groups the highest prevalence rate was $40.9 \%$ observed in age category of adult and the lowest prevalence rate $33.3 \%$ was observed in young. When body condition was considered as a risk factor for the prevalence of Paramphistomiasis 49.5\%, 30.8\% and 36.5\% was observed in poor, medium and good body condition respectively. The prevalence of paramphistomiasis in male (33.9\%), female (41.3\%) was recorded. This parasitic disease is distributed in every district and considered as one of the major setbacks to sheep product utilization causing direct and indirect losses.
\end{abstract}

Keywords: Paramphistomiasis; District; Kutaber; Prevalence

\section{Introduction}

Gastrointestinal parasitism is the major health problems severely limiting the productivity of animals [1]. Parasitism in sheep is a substantial problem plaguing farmers. Parasitic gastroenteritis continues to pose a serious health threat and limitation to the productivity of small ruminants due to associated morbidity, mortality, and cost of treatment and control measures on a clinical and sub-clinical level [2]. Due to improper care, unhygienic environment, extreme climate and close contact with infected animals, ruminants get infected with a variety of parasites [3].

Paramphistomiasis adversely affect ruminants, causing hematological and biochemical disturbances, anorexia, weight loss poor reproductive performance, leading to decrease resistance to diseases which can lead to and c even cause severe mortality thus leading to heavy loss [4]. Economically, a decrease in profitability of up to $15 \%$ and weight loss of up to $50 \%$ due to gastrointestinal parasite have been reported [5].

Paramphistomes play a vital role in ruminant diseases worldwide [6], with those commonly associated with diseases in sheep were identified to be Paraphisthomum (P) cervi, [7], principally cause anaemia.

Paramphistomosis (or amphistomosis) is a disease caused by digenean trematodes of Paramphistomatidae family parasitising the rumen of ruminants worldwide. Clinical disease is confined to warmer tropical and sub-tropical areas [8]. There are certain geographical regions in which livestock population needs to be examined for the presence of paramphistomum. But the overall occurrence of parasites of digestive tract, their variation in relation to age and sex of sheep and their seasonal dynamics was not studied adequately.

\section{The objectives of this study was}

a. To determine the prevalence Paraphisthomum

b. To know the relationship of Paramphistomiasis with age, sex, body condition

\section{Materials and Methods}

\section{Study area}

The study was conducted from November 2018 to April 2019 in selected rural district near Kutaber town to study the prevalence of ovine paramphistomiasis. Geographically the area is found in South Wollo zone, Amhara regional. It is located at 11012'36" -11018'36" N latitude and 39031'12" -39034'12" E longitude.

Kutaber area poses highland and lowland areas. The average minimum and maximum rainfall ranges between 500 and $955 \mathrm{ml}$ 
in short and long rainy season. The average annual temperature is $22^{\circ} \mathrm{C}$, [9]. Mixed agriculture is the main occupation of the population of the area. The major livestock reared in the area are sheep, goat, cattle and equine. According to statistical data, Kutaber Woreda has livestock population of 69720 cattle, 65 727sheep, 53304 goats, 18 005 Equines and 104737 chickens [10].

\section{Sample size determination}

To determine the sample size, a prevalence rate of $50 \%$ was taken into consideration since there was no research performed on ovine paramphistomiasis done in the area. The desired sample size for the study was calculated by using the formula given by Thrustfield [11] with 95\% Confidence interval and 5\% absolute precision.

$$
\mathrm{N}=(1.96)^{2} \times \mathrm{P}_{\exp }\left(1-\mathrm{P}_{\text {exp }}\right) / \mathrm{D}^{2}
$$

Where, $\mathrm{N}=$ Sample size;

$\mathrm{P}_{\exp }=$ Expected prevalence;

$\mathrm{D}^{2}=$ Absolute precision;

Then,

$$
\mathrm{N}=(1.96)^{2} \times 0.5(1-0.5)=384 /(0.05)^{2}
$$

\section{Sample collection}

Faecal samples were collected directly from the rectum of 384 sheep between November 2018 to april 2019. These animals were randomly selected from 5 nearby districts of Kutaber. Samples were transported to Kutaber Livestock Development Office, Veterinary Clinic, parasitology laboratory, for detailed coproscopic examination.

\section{Faecal examination}

Microscopic examinations of faecal samples were carried out using standard laboratory methods of sedimentation techniques. Eggs were identified using the light microscope and classified as described by Urquhart [7]

\section{Statistical analysis}

Data collected on prevalence and numbers of paramphistomiasis in faecal samples of sheep were statistically analyzed using SPSS statistics 20 software such as percentage and Chi square test. The test statistics (Chi Square) was applied at $\mathrm{P}<0.05$ level of significance.

\section{Results}

The overall prevalence of Paramphistomiasis in kutaber was $39.1 \%$. A total of 384 sheep were sampled in the area, 150 sheep were infected with paramphisthomum while 234 were negative. The prevalence of paramphistomiasis based on gender is found to have higher rate of infection in female 111 (41.3\%) than male 39 $(33.9 \%)$. There was statistically significant association $(\mathrm{P}<0.05)$ between occurrence of infection based on sex sampled.

The prevalence among different age groups was adult (40.9\%) and young (33.3\%). Prevalence of paramphistomiasis in different age groups of sheep was not significant $(\mathrm{P}>0.05)$ (Table 1 ).

\begin{tabular}{|c|c|c|c|}
\hline \multicolumn{3}{|c|}{ Table 1: Prevalence of ovine paramphistomiasis based on age. } \\
\hline Age group & $\begin{array}{c}\text { No of animals } \\
\text { examined }\end{array}$ & No of positive & $\begin{array}{c}\text { Prevalence } \\
\text { (\%) }\end{array}$ \\
\hline Young (<2 year) & 93 & 31 & $33.30 \%$ \\
\hline Adult (>2 year) & 291 & 119 & $40.90 \%$ \\
\hline Total & 384 & 150 & $39.10 \%$ \\
\hline
\end{tabular}

$\mathrm{X}^{2}=1.692, \mathrm{P}>0.05$ (Statically not significant)

The statistical analyses indicated that $33.9 \%$ of males and $41.3 \%$ of females were positive for the infection. Statically analysis showed that there was statistically significant $(\mathrm{P}<0.05)$ (Table 2).

\begin{tabular}{|c|c|c|c|}
\hline \multicolumn{4}{|c|}{ Table 2: prevalence of ovine paramphistomiasis based on sex. } \\
\hline Sex & No of animals examined & No of positive & Prevalence (\%) \\
\hline Female & 269 & 111 & $41.3 \%$ \\
\hline Male & 115 & 39 & $33.9 \%$ \\
\hline Total & 384 & 150 & $39.1 \%$ \\
\hline
\end{tabular}

$\left(\mathrm{X}^{2}=0.871, \mathrm{P}<0.05\right.$ (Statically significant)

On the present study area prevalence of paramphistomiasis were found to be higher in sheep with poor body condition than those with medium and good body condition with prevalence of

\begin{tabular}{|c|c|c|c|}
\hline $\begin{array}{l}\text { Body condition } \\
\text { score }\end{array}$ & $\begin{array}{c}\text { No of animals } \\
\text { examined }\end{array}$ & No of positive & $\begin{array}{c}\text { Prevalence } \\
(\%)\end{array}$ \\
\hline Poor & 149 & 74 & $49.70 \%$ \\
\hline Medium & 172 & 53 & $30.80 \%$ \\
\hline Good & 63 & 23 & $36.50 \%$ \\
\hline Total & 384 & 150 & $39.10 \%$ \\
\hline
\end{tabular}
$49.7 \%$. $30.8 \%$ and $36.5 \%$ respectively (Table 3 ).

$\left(\mathrm{X}^{2}=12.125, \mathrm{P}<0.05\right.$ (Statically significant)

\begin{tabular}{|c|c|c|c|}
\hline \multicolumn{3}{|c|}{ Table 4: prevalence of ovine paraphisthomiasis basesd on district } \\
\hline District & $\begin{array}{c}\text { No of animals } \\
\text { examined }\end{array}$ & No of positive & Prevalence (\%) \\
\hline Alansha & 41 & 8 & $19.50 \%$ \\
\hline Doshign & 124 & 40 & $32.30 \%$ \\
\hline Beshilo & 110 & 49 & $44.50 \%$ \\
\hline Lewcho & 90 & 45 & $50 \%$ \\
\hline Elesa & 19 & 8 & $42.10 \%$ \\
\hline Total & 384 & 150 & $39.10 \%$ \\
\hline
\end{tabular}

$\left(X^{2}=14.981, P<0.05\right.$ (Statically significant)).

The prevalence of ovine paramphistomiasis in 5 districts of Kutaber districts was Alansha (19.5\%), Doshign (32.3\%), Beshilo (44.5\%), Lewcho (50.0\%) and Elsa (42.1\%). The prevalence variation between studies District (Table 4) showed the highest and the lowest were $50.0 \%$ \& $19.5 \%$ in Lewcho and Alansha respectively.

\section{Discussion}

The overall prevalence of (39.1\%) paramphistomosis was found in small ruminant those were examined that reared in kutaber near by clinics. Lower findings were reported by Melaku 
and Addis [12] in Debrezeit to be $28.9 \%$ and Tsegabirhan [13] to be $23.7 \%$, in Ashange, Tigray.

The prevalence variation between studies District showed the highest and the lowest were $50.0 \%$ and 19.5\% in Lewcho and Alansha respectively. The main reason is due to variation in aggro ecology and awareness to use antihelmentics.

It was observed that the prevalence of paramphistomum infections was higher in females $(41.3 \%)$ than in male $33.9 \%)$ sheep. This finding is in agreement with the earlier study of Mazid [14] in Bangladesh who recorded higher prevalence of helminth infection in females than in male sheep. Similar trend of higher infestation rate reported in earlier work with goats where females (75.0\%) were found more susceptible to Paramphistomum infestation than males (67.5\%). Likewise, in another study, significantly higher prevalence in females (41.61\%) than males (27.45\%) were recorded [15].The reason for higher prevalence of paramphistomum infection in the females can be assumed that the alteration in the physiological condition of the females during pregnancy, lactation and parturition as well as stresses leading to immune suppression may be associated with this phenomenon. Higher level of prolactin and progesterone hormones makes the female individual more susceptible to any infection [16]. In other way the male were kept for a shorter period of time than female in the farmer house.

It was revealed that the prevalence of paramphistomum was higher in poor (49.7\%) than medium $(30.8 \%)$ and good $(36.5 \%)$ body conditioned sheep. This revealed that nutritional condition of sheep had significant $(\mathrm{p}<0.005)$ effect with paramphistomum infection. The higher prevalence of paramphistomum infection was recorded in poor (49.7\%) sheep than that in good (36.5\%) sheep. This finding is in agreement with the earlier study of Lapage [17] who found that malnourished animals are more susceptible to any infection as they are immunocompromised. The present study also agrees with the findings of Etter [17] who reported that in immunocompromised animal the fecundity of parasites is usually increased.

Age of the host had an effect on the prevalence of paramphistomum in sheep. The Prevalence of paramphisthomiasis was higher in adult sheep (40.9\%) than young (33.3\%). There was no statically significant difference ( $p>0.05$ ) in the prevalence of paramphisthomiasis with respect to the age. low infestation in young than adult sheep may be due to less exposure of the young sheep to the parasite than adult.

\section{Conclusion and Recommendations}

Paramphisthomiasis is a major obstacle for sheep productivity by imposing direct and indirect losses in Kutaber District. The study has investigated the prevalence of ovine paramphisthomiasis in sheep reared under extensive farming system in Kutaber district of the Amhara regional state, central Ethiopia. The result of the present study indicated that paramphisthomiasis is a higher prevalent sheep disease in the study area. This parasitic disease is distributed in every district and considered as one of the major setbacks to sheep product utilization causing direct and indirect losses. The findings of the current study revealed that paramphisthomiasis is still a health problem in the study area.

The present study suggests that;

campaigns on periodic dosing of sheep with anthelmintics

Improve herd health management practices

Avoid scarcity of feed.

\section{References}

1. Biu AA, Maimunatu A, Salamatu AF, Aghatu ET (2009) A fecal survey of gastrointestinal parasites of ruminants in the University of Maiduguri research farm. International Journal of Biomedical and Health Sciences 5(4): 175-179.

2. Martinez Gonzalez B, Diez Banos N, Rojo Vazquez FA (1998) An epidemiological study of gastrointestinal parasitism in dairy sheep flocks in Leon (NW) Spain. Small Ruminant Research 27(1): 25-30.

3. Gadahi JA, Arshed MJ, Ali Q, Javaid SB, Shah SI (2009) Prevalence of gastrointestinal parasites of sheep and goat in and around Rawalpindi and Islamabad, Pakistan. Veterinary World 2(2): 51-53.

4. Ngategize PK, Bekele T, Tilahun G (1993) Financial losses caused by ovine fasciolosis in the Ethiopian highlands. Trop Anim Health Prod 25(3): 155-161.

5. Shahnawaz M, Shahardar RA, Wani ZA (2011) Seasonal prevalence of platyhelminthosis of sheep in Ganderbal area of Kashmir Valley. Journal of Veterinary Parasitology 25(1): 59-62.

6. Soulsby EJL (1982) Helminths, Anthropods and Protozoa of Domesticated Animals, 7th Ed: Bailliere Tindall, London. pp: 66-71.

7. Urquhart GM, Armour J, JL Duncon JL, Dunn AM, FW Jennings (1987) Veterinary Parasitology. Longman Group UK Ltd., England, pp: 276-277.

8. Horak IG (1971) Paramphistomiasis of domestic ruminants. Adv Parasitol 9: 33-72.

9. KADO (2018) Kutaber Woreda Agriculture Development Office, South Wollo, Amhara Region.

10. KLRDO (2018) Kutaber Woreda Livestock Resource Development Office, South Wollo, Amhara Region.

11. Thrustfield M (2005) Veterinary epidemiology, $3^{\text {rd }}$ edn. Blackwell Science pp: 230-233.

12. Melaku S, Addis M (2012) Prevalence and intensity of Paramphistomum in Ruminants slaughtered at Debre-Zeit industrial Abattoir, Ethiopia. Global Veterinaria 8(3): 315-319.

13. Tsegabirhan K, Etsay K, Yohannes H, Kidane W, Messele G (2015) Prevalence of Paramphistomosis in ruminants in Ashenge, Tigray Ethiopia. Acta Parasitologica Globalis 6(2): 83-86.

14. Mazid MA, Bhattacharjee J, Begum N, Rahman MH (2006) Helminth parasites of the digestive system of sheep in Mymensingh, Bangladesh. Bangladesh Journal of Veterinary Medicine 4(2): 117-122.

15. Tariq KA, Chishli MY, lhmad F, Shaw IS (2008) Epidemiological study on Paramphistomum infection in goats- Kashmir Valley. World J Agric Sci 4(1): 61-66.

16. Lloyd S (1983) Effect of pregnancy and lactation up on infection. Veterinary immunology Immunopathology 4: 153-176.

17. Lapage G (1962) Monig's Veterinary Helminthology and Entomology. Bailiere, Tindall and Cox Ltd. London, UK pp:556-723.

18. Etter E, Chartier C, Hoste H, Borgida LP, Pors Isabelle, et al. (1999) The influence of nutrition on the peri parturient rise in fecal egg counts in dairy goat; results from a two years study. Review of veterinary medicine 150(12): 975-980.

19. Urquhart GM, Armour J, Duncan JL, Dunn AM, Jennings FW (1992) Veterinary Parasitology. Longman Group Ltd, London, UK. pp: 111-112. 